Exp. Anim. 63(4), 415-422, 2014

\title{
-Original-
}

\section{Gut Microbial Diversity in Rat Model Induced by Rhubarb}

\author{
Ying $\mathrm{PENG}^{1)}$, Chunfu WU ${ }^{2)}$, Jingyu YANG ${ }^{2)}$, and Xiaobo LI ${ }^{1)}$ \\ 1) School of Pharmacy, Shanghai Jiao Tong University, Shanghai 200030, P.R. China \\ ${ }^{2)}$ School of Pharmacy, Shenyang Pharmaceutical University, Shenyang 110016, P.R. China
}

\begin{abstract}
Rhubarb is often used to establish chronic diarrhea and spleen (Pi)-deficiency syndrome animal models in China. In this study, we utilized the enterobacterial repetitive intergenic consensuspolymerase chain reaction (ERIC-PCR) method to detect changes in bacterial diversity in feces and the bowel mucosa associated with this model. Total microbial genomic DNA from the small bowel (duodenum, jejunum, and ileum), large bowel (proximal colon, distal colon, and rectum), cecum, and feces of normal and rhubarb-exposed rats were used as templates for the ERIC-PCR analysis. We found that the fecal microbial composition did not correspond to the bowel bacteria mix. More bacterial diversity was observed in the ileum of rhubarb-exposed rats $(P<0.05)$. Furthermore, a 380 bp product was found to be increased in rhubarb-exposed rats both in faces and the bowel mucosa. The product was cloned and sequenced and showed high similarity with regions of the Bacteroides genome. AS a result of discriminant analysis with the SPSS software, the Canonical Discriminant Function Formulae for model rats was established.
\end{abstract}

Key words: animal model, bacterial diversity, ERIC-PCR, rhubarb

\section{Introduction}

Rhubarb (Rheum rhabarbarum) is a species of plant in the family Polygonaceae. Its roots and stems are rich in anthraquinones [27], such as emodin and rhein. These substances are cathartic and laxative. In the Chinese Pharmacopoeia [1], rhubarb is officially prescribed as the dried rhizome and root of $R$. palmatum L., $R$. tanguticum Maxim. ex Balf. and R. officinale Baill. of the family of Polygonaceae. Rhubarb has been used as a laxative for several thousand years and classified as "bitter-cold" in terms of taste and properties in traditional Chinese medicine (TCM). It is also officially listed in the European and Japanese Pharmacopoeias. Rhubarb exhibits a series of pharmacological activities and has been widely prescribed to treat gastrointestinal disease, hepatitis, blood diseases, chronic renal failure, and especially, constipation due to its effective purgative activity [20]. However, use of rhubarb as a purgative, when in a chronic state, will result in an imbalance in the intestinal microbiota and disturb the normal function of the body. As to its adverse effects [9], it is also used to induce chronic diarrhea and spleen (Pi)-deficiency syndrome in animal models in TCM studies [30]. Understanding the disequilibrium in the microbial diversity may be a key to understanding these diseases and successful establishment of animal models.

Fecal samples are often used to investigate the intestinal microbiota because they are easily collected and not invasive to the host. However, surface-attached and luminal microbial populations may be distinct in composition from the fecal population, and fulfill different roles within the ecosystem $[2,14,31]$. A number of new bacterial strains have been found in the murine intestinal tract that have not been detected in feces before [3, 22]. The degree to which the composition and function of the 
fecal bacteria differ from those of mucosal bacteria remains unclear. Molecular biological techniques, which are sensitive and efficient, have been recognized as potential and valuable tools for systematic and detailed assessment of microbial communities. They are likely to reveal new and unexpected principles of host biology and microbial ecology. Enterobacterial repetitive intergenic consensus-polymerase chain reaction (ERIC-PCR) fingerprinting is a PCR-based technique in which DNA is isolated from a mixed sample and amplified using conserved ERIC primers [25]. Slight changes in the composition of the microbial population used could theoretically result in very different PCR results [28]. Due to its sensitivity, the ERIC-PCR fingerprinting method may have implications in monitoring the effects of various known factors on the complex intestinal bacterial community $[4,7,23,24,26]$.

The aim of the present study was thus to reveal the changes in the bacterial composition of feces and the bowel mucosa associated with a rhubarb-induced rat model by using ERIC-PCR fingerprinting analysis and therefore gain more information on these animal models and to propose new routes by which to understand rhubarb-related diseases.

\section{Materials and Methods}

Animals

Wistar rats (weighed $200 \pm 20$ g, aged 7-8 weeks) of either sex were obtained from the Experimental Animal Centre of Fudan University (Shanghai, China). The rats were housed in a temperature $\left(25 \pm 2^{\circ} \mathrm{C}\right)$ and moisture $(55 \pm 10 \%)$ controlled room, exposed to a controlled 12-h light/dark cycle, and given ad libitum access to rodent lab diet and water. All animal experiments were performed in accordance with the guidelines for use of experimental animals established by Shanghai Jiao Tong University.

The rats acclimated to their environmental conditions for 4 days, and then they were randomly divided into two groups of eight. Group 1 (control group) received distilled water only $(10 \mathrm{ml} / \mathrm{kg}$, p.o.) during the whole experiment. Group 2 (model group) was intragastrically given rhubarb (Radix et Rhizoma Rhei extract, $1 \mathrm{~g} / \mathrm{ml}$ ) at $10 \mathrm{ml} / \mathrm{kg}$ twice a day for 10 days.

\section{Sample collection and DNA extraction}

Three or four fecal pellets (about $1 \mathrm{~g}$ ) per rat were directly collected from the anus into sterile plastic tubes and stored at $-20^{\circ} \mathrm{C}$ immediately. Fecal pellets were collected before and after inducement. After 10 days of inducement, rats were killed by decapitation, and samples of bowel (duodenum, D; jejunum, J; ileum, I; cecum, C; proximal colon, PC; distal colon, DC ; rectum, R) were taken from 16 rats.

The intestinal samples were infused and washed with 10 volume of sterile $0.05 \mathrm{M}$ PBS ( $\mathrm{pH}$ 7.4). The suspension was centrifuged at $300 \times \mathrm{g}$ for $6 \mathrm{~min}$, and the supernatant was transferred to a tube. To form a mixed sample, we mixed the supernatants of different intestinal parts. The fecal samples (about $0.2 \mathrm{~g}$ ) were suspended in $1 \mathrm{ml}$ sterile $0.05 \mathrm{M}$ PBS ( $\mathrm{pH}$ 7.4) followed by infusion and vortexing twice. After centrifugation at $200 \times \mathrm{g}$ to remove coarse particles, the supernatants were combined. The cells in the supernatant of feces or intestine were collected and washed twice with PBS by centrifugation at $10,000 \times \mathrm{g}$ for $6 \mathrm{~min}$, and the total DNA was isolated following the extraction protocol as described previously [16]. The DNA was checked for integrity by electrophoretic analysis on 1\% agarose gel (Agarose LE, MDBio, Inc., Taipei, Taiwan) (compared with sizeknown Hind III digested bacteriophage $\lambda$ DNA, Tiangen, Inc., Beijing, China).

\section{ERIC-PCR fingerprint}

ERIC-PCR was performed as previously described [16]. ERIC primers (ERIC1R, 5'-ATG TAA GCT CCT GGG GAT TCAC-3'; ERIC2, 5'-AAG TAA GTG ACT GGG GTG AGCG-3') were used. PCR products were resolved by electrophoresis in $2 \%$ agarose gel containing $0.5 \mu \mathrm{g} / \mathrm{ml}$ ethidium bromide and visualized under UV light with Tannon GIS2010 Image System Ver. 3.73 (Tanon, Inc., Shanghai, China). The size and quantity of the amplified fragments were determined using $1 \mathrm{~kb}$ Plus DNA Makers (Tiangen, Inc., Beijing, China).

\section{Cloning procedures}

Gel slices containing the individual signature DNA bands were excised and purified using a commercial gel extraction kit (Qiagen, Valencia, CA). The purified fragments were ligated with PMD18-T vector (Takara, Dalian, China) and transformed into E. coli JM109 Cells (Takara, Dalian, China). Cloned gene fragment was reamplified with M13 forward (5'-CGCCAGGGTTTTCCCAGTCACGAC-3') and reverse (5'-AGCGGATAACAATTTCACACAGGA-3') primers 

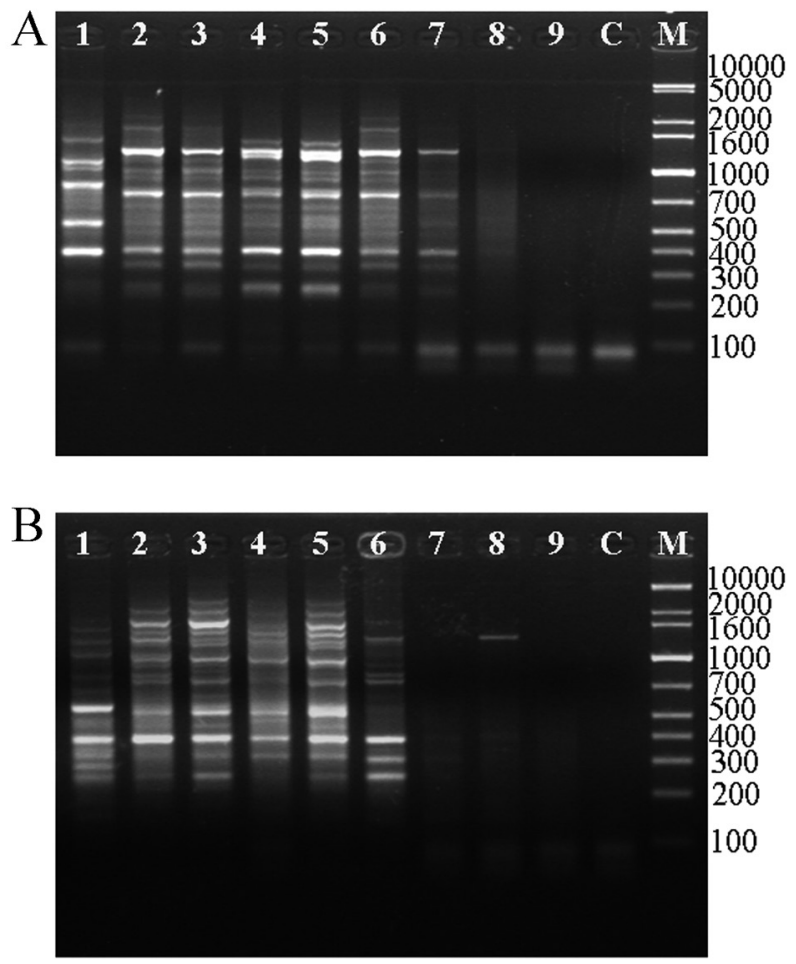

Fig. 1. Electrophoresis profiles of ERIC-PCR fingerprinting for feces and different intestinal sites of rhubarb-exposed (A) and normal (B) rats. 1, fecal sample; 2, mixture of intestinal samples; 3 , rectum sample; 4 , distal colon sample; 5 , proximal colon sample; 6 , cecum sample; 7, ileum sample; 8 , jejunum sample; 9 , duodenum sample; $\mathrm{C}$, control; $\mathrm{M}$, $1 \mathrm{~kb}$ Plus ladder

and selected for sequencing (Invitrogen, Shanghai, China). The sequences were analyzed with the BLAST program at the NCBI website (http://www.ncbi.nlm.nih. gov/blast).

\section{Data analysis}

The bands on the gel were transformed into data sets by the Gel Compare function of Tannon GIS2010 Image System Ver. 3.73. Furthermore, Sorenson's pairwise similarity coefficient $(\mathrm{Cs})[8,11]$ and the Shannon Index $\left(H^{\prime}\right)[8,11,21]$ were employed to measure the similarities of composition or distribution diversities of microbial ecosystems, although each ERIC-PCR band does not have to stand for one individual bacterial species. In order to identify the effect of different parameters on discriminating between normal and rhubarb-exposed rats, discriminant analysis was performed and evaluated using the SPSS version 11.5 software (Statistical Package for the Social Sciences, SPSS Inc., Chicago, IL, a

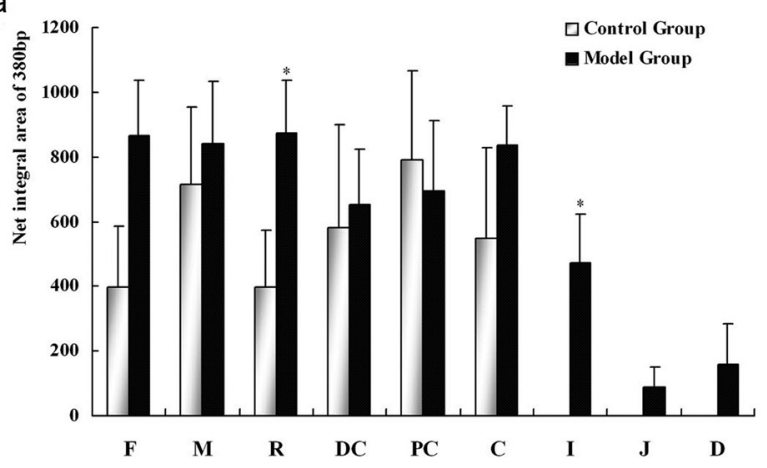

b

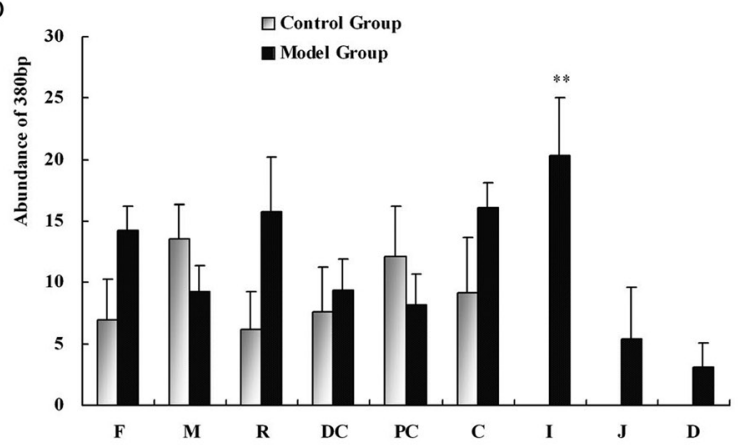

c

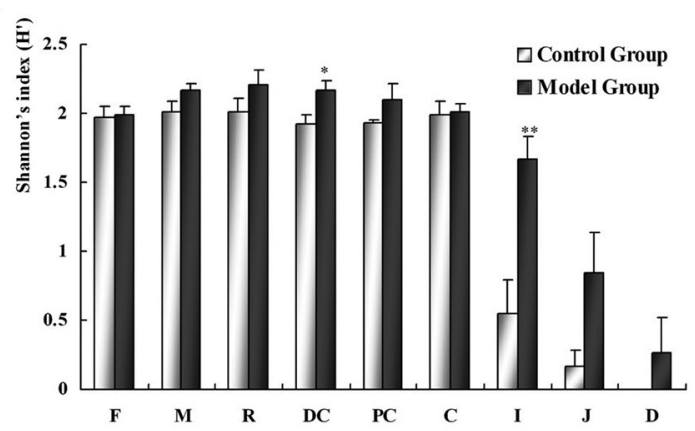

Fig. 2. Net integral area (a), abundance of the $380 \mathrm{bp}$ product (b) and Shannon index (c) of ERIC-PCR fingerprinting of different samples in the control and model groups after inducement. $* P<0.05, * * P<0.01$, paired samples $t$-test, contrasted with the control group. F, fecal sample; M, mix of intestinal samples; $\mathrm{R}$, rectum sample; DC, distal colon sample; PC, proximal colon sample; C, cecum sample; I, ileum sample; J, jejunum sample; D, duodenum sample.

USA). Results are presented as means \pm SEM. Statistical significance was determined using paired-samples $t$-test or ANOVA, where appropriate. Values with $P<0.05$ were considered significant. 
Table 1. Cs matrix of ERIC-PCR fingerprint obtained from feces and different intestinal sites in normal rat $(\mathrm{n}=8)$

\begin{tabular}{|c|c|c|c|c|c|c|c|c|}
\hline \multirow[b]{2}{*}{ Sample } & \multicolumn{8}{|c|}{$\mathrm{Cs} \% \pm \mathrm{SD} \%$} \\
\hline & Fecal & $\begin{array}{l}\text { Intestinal } \\
\text { mixture }\end{array}$ & Rectum & Distal colon & $\begin{array}{l}\text { Proximal } \\
\text { colon }\end{array}$ & Caecum & Ileum & Jejunum \\
\hline Intestinal mixture & $61.98 \pm 12.52$ & & & & & & & \\
\hline Rectum & $64.90 \pm 8.63$ & $61.03 \pm 11.78$ & & & & & & \\
\hline Distal colon & $63.44 \pm 11.66$ & $62.48 \pm 7.92$ & $68.46 \pm 9.54$ & & & & & \\
\hline Proximal colon & $63.04 \pm 17.48$ & $70.84 \pm 11.29$ & $72.00 \pm 10.90$ & $88.40 \pm 8.28$ & & & & \\
\hline Caecum & $66.74 \pm 10.57$ & $60.55 \pm 13.96$ & $64.38 \pm 13.99$ & $65.23 \pm 10.19$ & $71.43 \pm 13.22$ & & & \\
\hline Ileum & $16.58 \pm 18.02$ & $20.09 \pm 23.17$ & $22.55 \pm 27.69$ & $20.09 \pm 23.77$ & $22.23 \pm 24.58$ & $23.61 \pm 25.33$ & & \\
\hline Jejunum & $10.62 \pm 15.29$ & $9.26 \pm 15.72$ & $7.67 \pm 14.52$ & $8.40 \pm 11.67$ & $10.28 \pm 15.35$ & $9.03 \pm 18.29$ & $42.50 \pm 49.50$ & \\
\hline Duodenum & $6.25 \pm 17.68$ & 0 & $5.00 \pm 14.14$ & $2.50 \pm 7.07$ & $2.50 \pm 7.07$ & $1.92 \pm 5.44$ & $37.50 \pm 51.75$ & $62.50 \pm 51.75$ \\
\hline
\end{tabular}

\section{Results}

ERIC-PCR profiles of feces and the intestinal tract in normal rats

The PCR products amplified with ERIC primers yielded $8-13$ bands mainly ranging in size from 250 to $2,000 \mathrm{bp}$ in fecal, large bowel (proximal colon, distal colon, rectum), and cecum samples, while only $0-5$ bands were found in the small bowel (duodenum, jejunum, ileum) samples (Figs. 1A and B). Comparison of feces and different bowel sections by calculation of the Cs obtained from ERIC-PCR revealed that there were marked differences in fecal bacterial composition with the cecum, proximal colon, distal colon, and rectum, as their similarities ranged from $62 \%$ to $67 \%$ (Table 1), although the Shannon indexes of these samples were not obviously altered (Fig. 2c). As few microbes exit in the small bowel, the diversities $\left(H^{\prime}\right)$ of these microbial communities were low, and the similarity values for feces were lower. To better understand the differences in bacterial population between feces and the intestinal tract, a mixture including small bowel, large bowel, and cecum samples was analyzed, and the bacterial population of the mixture was found to be different from that of feces, although the similarities in the bacterial populations of the different bowel sections compared with those of feces paralleled with those of the mixture (Table 1).

\section{Alteration of bacterial composition in feces and the intestinal tract of rhubarb-exposed rats}

To monitor the changes in the intestinal microbiota in response to rhubarb, ERIC-PCR fingerprints obtained from the feces collected before and after inducement were compared. The diversity $\left(H^{\prime}\right)$ of the rhubarb-exposed rats was significantly decreased after inducement, and a significant increase in abundance and net integral area of a $380 \mathrm{bp}$ product was observed $(P<0.05)$, while no obvious changes in these parameters were shown in normal rats (Fig. 3). Moreover, the similarity before and after inducement of rhubarb-exposed rats was significantly decreased $(45.38 \pm 15.52 \%)$ compared with the case in normal rats $(85.70 \pm 5.77 \%, P<0.01)$, which suggested that the composition of the microbiota in the model rats was altered.

In accordance with this, comparative ERIC-PCR profiles obtained from bowel sections also showed an increase in abundance and net integral area of the $380 \mathrm{bp}$ product in rhubarb-exposed rats, especially in the ileum section $(P<0.05$ and $P<0.01$, Figs. $2 \mathrm{a}$ and $\mathrm{b})$. The Shannon index $\left(H^{\prime}\right)$ for the ileum in the rhubarb-exposed rats was also significantly raised, and its similarity with feces, the large bowel, and the cecum was correspondingly increased, demonstrating that there are more microbes in the proximal bowel of the model rats.

The bowel mixtures of the rhubarb-exposed rats were also analyzed and compared to feces as in the case of the normal group case. As shown in Table 2, the similarity between mixtures and feces was only $63.65 \pm 8.94 \%$, indicating a difference in bacteria composition between the intestinal tract and feces.

\section{Cloned sequence of the $380 \mathrm{bp}$ product}

The fragments of the $380 \mathrm{bp}$ product were purified and ligated into PMD18-T vectors and transformed into $E$. coli JM109 Cells. Forty clones originating from four rhubarb-treated rats were analyzed, and similarity searches of the GenBank database were performed using BLAST in an attempt to identify known homologous sequences for the cloned fragments. The results showed that there were 10 different fragments in these clones, and one was found to share $70-99 \%$ homology at the nucleic acid level with regions of the Bacteroides ge- 

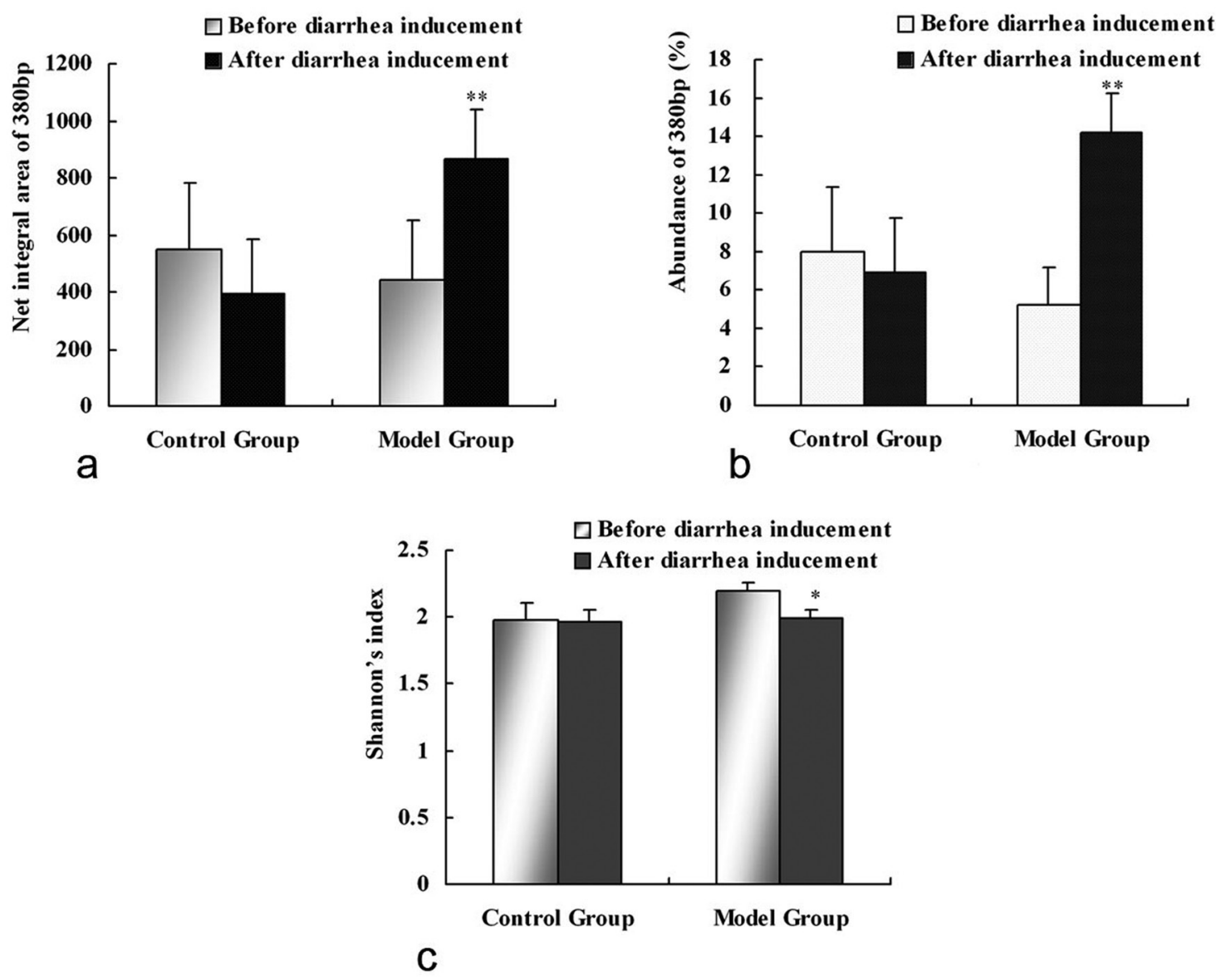

Fig. 3. Net integral area (a), abundance of the $380 \mathrm{bp}$ product (b) and Shannon index (c) in fecal samples before and after inducement in the control and model groups. ${ }^{*} P<0.05$, $* * P<0.01$, paired Samples $t$-test, contrasted with before administration.

nome, especially Bacteroides vulgatus ATCC 8482. Two sequences were found to share $74 \%$ homology with regions of the Salmonella enterica subsp genome, and two were found to share $80 \%$ homology with regions of the Uncultured bacterium clone LMOABA36ZH1ORM1 sequence and synchronously $70-75 \%$ homology with regions of the Bacteroides genome. For the other fragments, however, no significant hit was found. This might indicate that they derived either from an unknown bacterium or a known bacterium that is poorly understood at the genomic level.

Discriminant analysis of normal and rhubarb-exposed rats

To clarify the effect of parameters (Shannon index, net integral area, and abundance of the $380 \mathrm{bp}$ product) on discriminating between normal and rhubarb-exposed rats, we conducted discriminant analysis using the SPSS software. The Canonical Discriminant Function Formulae with three parameters of feces, each parameter of feces, and different bowel sections were determined respectively. A coefficient of more than zero was considered to indicate the model animal status; otherwise, the status was considered to be normal. The validity rates of the formulae were $81.3,100,93.8$, and $87.5 \%$, respectively (Table 3). Among the feces and different bowel sections, the ileum was significantly contributed to discriminating between normal and model rats $(P<0.05)$.

\section{Discussion}

Molecular biological techniques have enabled a good assessment of the microbiota composition and could provide an opportunity to determine the compositions of different sites of the gut. They are also useful tools for comparing the bacterial composition associated with 
Table 2. Cs matrix of ERIC-PCR fingerprints obtained from feces and different intestinal sites in model rat $(\mathrm{n}=8)$

\begin{tabular}{|c|c|c|c|c|c|c|c|c|}
\hline \multirow[b]{2}{*}{ Sample } & \multicolumn{8}{|c|}{$\mathrm{Cs} \% \pm \mathrm{SD} \%$} \\
\hline & Fecal & Intestinal mix & Rectum & Distal colon & $\begin{array}{l}\text { Proximal } \\
\text { colon }\end{array}$ & Caecum & Ileum & Jejunum \\
\hline Intestinal mixture & $63.65 \pm 8.94$ & & & & & & & \\
\hline Rectum & $59.66 \pm 9.64$ & $69.64 \pm 10.70$ & & & & & & \\
\hline Distal colon & $60.26 \pm 9.34$ & $69.90 \pm 20.45$ & $73.07 \pm 12.40$ & & & & & \\
\hline Proximal colon & $52.93 \pm 7.58$ & $68.39 \pm 21.57$ & $72.16 \pm 18.56$ & $77.16 \pm 16.57$ & & & & \\
\hline Caecum & $53.36 \pm 11.17$ & $67.25 \pm 13.99$ & $69.63 \pm 12.08$ & $60.56 \pm 12.44$ & $63.97 \pm 5.37$ & & & \\
\hline Ileum & $39.43 \pm 12.84$ & $45.20 \pm 23.67$ & $44.26 \pm 20.32$ & $50.24 \pm 17.01$ & $49.04 \pm 20.00$ & $57.07 \pm 20.78$ & & \\
\hline Jejunum & $10.93 \pm 15.30$ & $26.64 \pm 27.69$ & $18.69 \pm 18.91$ & $21.54 \pm 20.13$ & $25.21 \pm 25.40$ & $27.13 \pm 28.02$ & $36.78 \pm 38.49$ & \\
\hline Duodenum & $7.55 \pm 16.63$ & $13.33 \pm 25.70$ & $9.63 \pm 18.41$ & $13.16 \pm 24.36$ & $12.53 \pm 23.24$ & $14.18 \pm 27.28$ & $17.76 \pm 36.35$ & $63.09 \pm 43.47$ \\
\hline
\end{tabular}

Table 3. Canonical Discriminant Function Formulae determined by Discriminant Analysis using the SPSS software

\begin{tabular}{|c|c|c|}
\hline Parameter & Canonical Discriminant Function Formulae & $\begin{array}{l}\text { Validity } \\
\text { Rate (\%) }\end{array}$ \\
\hline Fecal sample & $\mathrm{X}=-9.345-0.002 \mathrm{~N}+0.245 \mathrm{~A}+4.095 \mathrm{H}^{\dagger}$ & $81.30 \%$ \\
\hline Net integral area of $380 \mathrm{bp}$ & $\mathrm{X}=-1.462+0.003 \mathrm{~F}+0.001 \mathrm{M}+0.003 \mathrm{DC}-0.005 \mathrm{PC}+0.004 \mathrm{I}+0.016 \mathrm{~J}-0.007 \mathrm{D}$ & $100 \%$ \\
\hline Abundance of $380 \mathrm{bp}$ & $\mathrm{X}=-1.822+0.129 \mathrm{~F}-0.078 \mathrm{M}-0.017 \mathrm{R}+0.061 \mathrm{DC}-0.073 \mathrm{PC}+0.055 \mathrm{C}+0.087 \mathrm{I}-0.034 \mathrm{~J}+0.175 \mathrm{D}$ & $93.80 \%$ \\
\hline Shannon's Index & $\mathrm{X}=-19.614+0.416 \mathrm{~F}+4.658 \mathrm{M}+2.870 \mathrm{R}-0.370 \mathrm{DC}+0.630 \mathrm{PC}+0.453 \mathrm{C}+1.512 \mathrm{I}-0.221 \mathrm{~J}+0.205 \mathrm{D}$ & $87.50 \%$ \\
\hline
\end{tabular}

$\dagger \mathrm{N}$ - Net integral area of product 380bp in feces; A- Abundance of product 380bp in feces; H- Shannon's Index in feces. $\$$ F-Fecal sample; M-Mix of intestinal samples; R-Rectum; DC-Distal colon; PC-Proximal colon; C-Caecum; I-Ileum; J-Jejunum; D-Duodenum.

the development of intestinal diseases, as they might provide clues to identity gut residents involved in the pathogenesis of these diseases and clarify the characteristics of disease models $[12,15]$. ERIC-PCR is a rapid and highly discriminating method and has implications in monitoring the effects of various known factors such as dietary change, stress, exercise, age, drug treatment, and disease on the complex intestinal microbiota. It is highly reproducible when it is used to examine the status of the intestinal microbiota in rats $[16,17]$. In our study, the Cs for the PCRs from triplicate DNA extractions was above $90 \%$, and that for triplicate PCRs from the same DNA extraction was higher than $95 \%$. However, due to interindividual variation between the rats, there was considerable variation of ERIC-PCR profiles within groups, in which only approximately $50 \%$ similarity was seen.

The inducement with rhubarb appeared to alter the balance of the microbial ecosystem and ultimately resulted in both increases and decreases in the abundances of various species in different gastrointestinal locations. These changes may be explained by antibacterial and purgative activities of rhubarb. Previous studies have demonstrated that a 380 bp product showed a significant increase in fecal ERIC-PCR fingerprints of spleen (Pi)deficient rats induced with rhubarb or Folium Sennae
[17]. In the present study, this change was also detected in the intestinal tract. As the 380 bp product was also found in normal rats, we suggested that it may belong to the resident gut microbiota and act as an opportunistic pathogen under favorable conditions. The results of cloning indicated that it had some relationship with Bacteroides, Salmonella, or an uncultured bacterium. Bacteroides species largely exist in hosts and are significant with respect to host health. However, they are also pathogens conditioned to make the host ill when the microbial balance of the host body is changed [29]. The genus Salmonella belongs to the family Enterobacteriaceae, and many of its strains are important human and animal gastrointestinal pathogens [6].

Site-specific colonization in the gastrointestinal tract may be contributory to the etiology of some diseases of the intestine. This may be one of the pathogeneses of the rhubarb animal model. More bacterial diversity was found in the ileum of rhubarb-exposed rats, indicating that small intestinal bacterial overgrowth (SIBO) may have been created by the inclusion of rhubarb. SIBO refers to a condition in which abnormally large numbers of anaerobic bacteria are present in the small intestine, and patients with SIBO typically complain of diarrhea, bloating, and some symptoms induced by malabsorption and dysfunction of the intestinal transit [18]. Anything 
that interferes with the normal muscular activity in the small intestine can result in SIBO. Simply stated, any condition that interferes with muscular activity in the small intestine allows the bacteria to stay longer and multiply in the small intestine. The lack of muscular activity also may allow bacteria to spread backwards from the colon and into the small intestine [10].

A large number of studies have been performed to investigate fecal bacterial composition and changes because of their accessibility. However, its composition and changes have been demonstrated to differ from those of the intestinal mucosa in humans, pigs, and mice $[5,13,19,31]$. Our data indicated that a large variance in bacterial composition existed between feces and different sections of the intestinal tract in both normal and model rats. Moreover, the fecal microbial composition did not correspond to that of an intestinal mixture, with the similarity being $60 \%$.

\section{Acknowledgments}

This work was supported by the National Natural Science Foundation of China (no. 90209059,90409018).

\section{References}

1. 2010. Pharmacopoeia of the People's Republic of China, First Div. pp. 22-23. China Chemical Industry Press, Beijing, (in Chinese).

2. Ahmed, S., Macfarlane, G.T., Fite, A., McBain, A.J., Gilbert, P. and Macfarlane S. 2007. Mucosa-associated bacterial diversity in relation to human terminal ileum and colonic biopsy samples. Appl. Environ. Microbiol. 73: 7435-7442. [Medline]

3. Dalby, A.B., Frank, D.N., St Amand, A.L., Bendele, A.M., and Pace, N.R. 2006. Culture-independent analysis of indomethacin-induced alterations in the rat gastrointestinal microbiota. Appl. Environ. Microbiol. 72: 6707-6715. [Medline] [CrossRef]

4. Van Driessche, E., Houf, K., Vangroenweghe, F., De Zutter, L., and Van Hoof, J. 2005. Prevalence, enumeration and strain variation of Arcobacter species in the faeces of healthy cattle in Belgium. Vet. Microbiol. 105: 149-154. [Medline] [CrossRef]

5. Eckburg, P.B., Bik, E.M., Bernstein, C.N., Purdom, E., Dethlefsen, L., Sargent, M., Gill, S.R., Nelson, K.E., and Relman, D.A. 2005. Diversity of the human intestinal microbial flora. Science 308: 1635-1638. [Medline] [CrossRef]

6. Kim, S., Frye, J.G., Hu, J., Fedorka-Cray, P.J., Gautom, R., and Boyle, D.S. 2006. Multiplex PCR-based method for identification of common clinical serotypes of Salmonella enterica subsp. enterica. J. Clin. Microbiol. 44: 3608-3615. [Medline] [CrossRef]
7. Kong, J., Li, X.B., and Wu, C.F. 2006. A molecular biological method for screening and evaluating the traditional Chinese medicine used in Pi-deficiency therapy involving intestinal microflora. Asian J. Trad. Med. 1: 1-6.

8. Li, F., Hullar, M.A.J., and Lampe, J.W. 2007. Optimization of terminal restriction fragment polymorphism (TRFLP) analysis of human gut microbiota. J. Microbiol. Methods 68: 303-311. [Medline] [CrossRef]

9. Li, G., Xiao, X.H., Jin, C., and Li, Z.L. 2007. Averse effect of Radix et Rhizoma Rhei in ancient and modern times. China J. Trad. Chin. Med. Pharm. Chin. 22: 439-442.

10. Lin, H.C. 2004. Small intestinal bacterial overgrowth: a framework for understanding irritable bowel syndrome. JAMA 292: 852-858. [Medline] [CrossRef]

11. McCracken, V.J., Simpson, J.M., Mackie, R.I., and Gaskins, H.R. 2001. Molecular ecological analysis of dietary and antibiotic-induced alterations of the mouse intestinal microbiota. J. Nutr. 131: 1862-1870. [Medline]

12. Ott, S.J., Musfeldt, M., Wenderoth, D.F., Hampe, J., Brant, O., Fölsch, U.R., Timmis, K.N., and Schreiber, S. 2004. Reduction in diversity of the colonic mucosa associated bacterial microflora in patients with active inflammatory bowel disease. Gut 53: 685-693. [Medline] [CrossRef]

13. Ouwehand, A.C., Salminen, S., Arvola, T., Ruuska, T., and Isolauri, E. 2004. Microbiota composition of the intestinal mucosa: association with fecal microbiota? Microbiol. Immunol. 48: 497-500. [Medline] [CrossRef]

14. Palmer, C., Bik, E.M., Eisen, M.B., Eckburg, P.B., Sana, T.R., Wolber, P.K., Relman, D.A., and Brown, P.O. 2006. Rapid quantitative profiling of complex microbial populations. Nucleic. Acids. Res. 34: e5. [Medline] [CrossRef]

15. Pan, L., Du, H.M., Huang, H.D., Wei, G.F., Chen, J.Y., and Zhao, L.P. 2003. ERIC-PCR fingerprinting of structural features of microbial communities in children's intestines with different types of diarrhea. Chin. J. Microecol. Chin. 115: $141-143$

16. Peng, Y., Jin, J., Wu, C., Yang, J., and Li, X. 2007. Orthogonal array design in optimizing ERIC-PCR system for fingerprinting rat's intestinal microflora. J. Appl. Microbiol. 103: 2095-2101. [Medline] [CrossRef]

17. Peng, Y., Wang, Z., Lu, Y., Wu, C.F., Yang, J.Y., and Li, X.B. 2009. Intestinal microflora molecular markers of spleen-deficient rats and evaluation of traditional Chinese drugs. World J. Gastroenterol. 15: 2220-2227. [Medline] [CrossRef]

18. Posserud, I., Stotzer, P.O., Björnsson, E.S., Abrahamsson, H., and Simrén, M. 2007. Small intestinal bacterial overgrowth in patients with irritable bowel syndrome. Gut 56: 802-808. [Medline] [CrossRef]

19. Pryde, S.E., Richardson, A.J., Stewart, C.S., and Flint, H.J. 1999. Molecular analysis of the microbial diversity present in the colonic wall, colonic lumen, and cecal lumen of a pig. Appl. Environ. Microbiol. 65: 5372-5377. [Medline]

20. Qin, Y., Wang, J.B., Kong, W.J., Zhao, Y.L., Yang, H.Y., Dai, C.M., Fang, F., Zhang, L., Li, B.C., Jin, C., and Xiao, X.H. 2011. The diarrhoeogenic and antidiarrhoeal bidirectional effects of rhubarb and its potential mechanism. J. Ethnopharmacol. 133: 1096-1102. [Medline] [CrossRef]

21. Scanlan, P.D., Shanahan, F., O’Mahony, C., and Marchesi, 
J.R. 2006. Culture-independent analyses of temporal variation of the dominant fecal microbiota and targeted bacterial subgroups in Crohn's disease. J. Clin. Microbiol. 44: 39803988. [Medline] [CrossRef]

22. Vaahtovuo, J., Toivanen, P., and Eerola, E. 2003. Bacterial composition of murine fecal microflora is indigenous and genetically guided. FEMS Microbiol. Ecol. 44: 131-136. [Medline] [CrossRef]

23. Ventura, M., Meylan, V., and Zink, R. 2003. Identification and tracing of Bifidobacterium species by use of enterobacterial repetitive intergenic consensus sequences. Appl. Environ. Microbiol. 69: 4296-4301. [Medline] [CrossRef]

24. Ventura, M. and Zink, R. 2002. Specific identification and molecular typing analysis of Lactobacillus johnsonii by using PCR-based methods and pulsed-field gel electrophoresis. FEMS Microbiol. Lett. 217: 141-154. [Medline] [CrossRef]

25. Versalovic, J., Koeuth, T., and Lupski, J.R. 1991. Distribution of repetitive DNA sequences in eubacteria and application to fingerprinting of bacterial genomes. Nucleic Acids Res. 19: 6823-6831. [Medline] [CrossRef]

26. Wei, G., Pan, L., Du, H., Chen, J., and Zhao, L. 2004. ERICPCR fingerprinting-based community DNA hybridization to pinpoint genome-specific fragments as molecular markers to identify and track populations common to healthy human guts.
J. Microbiol. Methods 59: 91-108. [Medline] [CrossRef]

27. Wei, S.Y., Yao, W.X., Ji, W.Y., Wei, J.Q., and Peng, S.Q. 2013. Qualitative and quantitative analysis of anthraquinones in rhubarbs by high performance liquid chromatography with diode array detector and mass spectrometry. Food Chem. 141: 1710-1715. [Medline] [CrossRef]

28. Wilson, L.A. and Sharp, P.M. 2006. Enterobacterial repetitive intergenic consensus (ERIC) sequences in Escherichia coli: Evolution and implications for ERIC-PCR. Mol. Biol. Evol. 23: 1156-1168. [Medline] [CrossRef]

29. Wu, Y.B., Li, Y.D., Li, X.J., and Bian, Y.Q. 2007. The Study and Application on Bacteroides. Biotechnol. Bull. Chin. 1: 66-69.

30. Zhu, S. 2003. Experimental research on the effects of Jianpizhixie granules on the intestinal flora and small intestine mucosa in mice with diarrhea of splenic deficiency type. $J$. Beijing Univer. Trad. Chin. Med. Chin. 26: 28-30.

31. Zoetendal, E.G., von Wright, A., Vilpponen-Salmela, T., Ben-Amor, K., Akkermans, A.D.L., and de Vos, W.M. 2002. Mucosa-associated bacteria in the human gastrointestinal tract are uniformly distributed along the colon and differ from the community recovered from feces. Appl. Environ. Microbiol. 68: 3401-3407. [Medline] [CrossRef] 